\title{
Climate Change and Technical Progress: Impact of Informational Constraints
}

\author{
Anton Bondarev, Christiane Clemens, Alfred Greiner
}




\title{
Climate Change and Technical Progress: Impact of Informational Constraints
}

\author{
Anton Bondarev, Christiane Clemens, and Alfred Greiner*
}

\begin{abstract}
In this paper we analyse a growth model that includes environmental and economic variables as well as technological progress under different informational constraints on the behavior of economic agents. To simulate the informationally constrained economy, we make use of the non-linear model predictive control technique. We compare models with exogenous and endogenous technical change as well as directed and undirected endogenous technical change under different informational structures. We show that endogenous technical change yields lower environmental damages than exogenous technical change with fully informed agents. At the same time, welfare may rise or decline depending on the efficiency of the technology in use. In the case of directed technical change, a green growth scenario generates a smaller temperature increase that, however, goes along with less output and lower welfare. This holds both for informationally constrained and unconstrained behaviour of agents. We find that the effects of informational constraints, with respect to the climate system, increase with the degree of endogeneity of technology in the model.
\end{abstract}

Keywords: Environmental economics, endogenous growth, directed technical change, model predictive control

\footnotetext{
* Department of Business Administration and Economics, Bielefeld University, Universitätstraße 25,33615 Bielefeld, Germany, e-mail: abondarev@wiwi.uni-bielefeld.de, cclemens@wiwi.unibielefeld.de, agreiner@wiwi.uni-bielefeld.de

Authors thank A. Belyakov and V. Veliov for their advice with numeric algorithms. Financial support from the Bundesministerium für Bildung und Forschung (BMBF) is gratefully acknowledged (grant 01LA1105C). This research is part of the project 'Climate Policy and the Growth Pattern of Nations (CliPoN)'.
} 


\section{Introduction}

In this paper we develop the simple dynamic endogenous growth model of the world economy which takes into account environmental damages. There are a great many such models in the literature, starting with the seminal paper by Nordhaus, [12]. Some of these models are of integrated assessment type (IAM) and employ the detailed description of the economy under consideration together with many sectors and parameters which are then estimated. Other types of models are of simpler structure and are employed to study some new approaches to the modelling of environment in endogenous growth theory. In this second strand of literature there are two different approaches to modelling environmental damages and environmental threat for the economy: through the inclusion of environmental quality into the utility function of the representative household, as in the paper by Ligthart and Van Der Ploeg, [11], or through the assumption of productivity decrease due to the environmental degradation, or both. An example of such an approach is the paper by Lans, [10], where the notion of pollution-augmenting technical change is adopted. According to this classification, our paper belongs to the second approach.

The main focus of this paper is the influence of different forms of technical change on the evolution of the economy and on the environment under different informational regimes for the economy. Hence, there are two main departures from the majority of the literature on endogenous growth taking into consideration the environment. The first concerns the way the technological change is modelled and, the second, the way the agent takes into account the environmental change in his/her decision making.

As concerns the first aspect, the technology in environmental models was usually modelled as an exogenous process of accumulation of knowledge according to some given function, without any influence from the part of the optimizing agent. Later on, there appeared a number of papers where the environmental variables are subject to the control of the agent together with the technology. These papers build up upon two well-known models of endogenous growth, namely that of Romer [13] and that of Aghion and Howitt [2]. As an example for an endogenous growth model with environmental damages, based on variety expansion, one may take the paper by Barbier [4], while papers by Grimaud [6, 7, 8] are based on the model of vertical innovations by Aghion and Howitt [2]. These and similar papers do not take into account the environmental friendliness of technologies being developed and deal only with productivity. At the same time, there is a discussion in the literature on the possibility of "green growth", where the productivity increase of the economy does not lead to environmental damages. In recent years, endogenous growth models have appeared that distinguish between "clean" and "dirty" technologies. This type of modelling uses the notion of directed technical change and the most recent example of such a literature is the paper by Acemoglu et al. [1]. The natural question one may ask is: what additional insight and implications follow from the inclusion of directed technical change into such a model. To answer it, we employ the same strategy as in the early paper by Smulders [14] and compare three simplified models in their predictions. We compare the results of the model with 
exogenous technical change, similar to the one employed in the paper of Bréchet, Camacho and Veliov [5], with those of undirected but endogenous technical change in the spirit of papers by Barbier and Grimaud $[4,6]$ and with the outcome of the model featuring directed endogenous technical change with similar ideas as in Acemoglu et al. [1]. We come to the conclusion that in the absence of external stimuli, the agent will choose the more productive technology with higher environmental damages, rather than the cleaner one under directed technical change. At the same time, with undirected exogenous technical change, environmental damages may be lower than under directed change, given the "dirty" sceanrio of the economy.

Another aspect of interest for our research is the comparison of performance of the model under different informational regimes being allowed for. To this end, we employ the non-linear model predictive control (NMPC) approach which has been proposed for the environmental growth model in the paper by Bréchet et al. [5], while developed earlier on in the literature on the NMPC technique, see the collection of contributions in Allgöwer and Zheng [3] for reference. We compare the results of the model with an "optimal" (Pareto-optimal) behaviour of the agent, who cares about the environment to a full extent acting as a perfect-foresighted individual, with the outcome of an individual with limited rationality, modelled as a receding planning horizon of the agent. It turns out that under receding horizon decision rules, the difference in terms of social welfare and environmental degradation between smart management of endogenous directed and undirected technological change and exogenously given pattern of technology is higher, compared to full information regime rules. At the same time, the directed technical change differs to a lesser extent from the undirected endogenous one (again in terms of welfare and environment) under informational constraints than under the full information regime. These differences in ordering of social welfare under different decision rules may help us to clarify the role that the managment of technological progress plays with respect to the urgently desired switch of the equilibrium dynamics towards cleaner growth policies.

The rest of the paper is organised as follows. In the next section the formal description of all three versions of the model is given together with some necessary comments on the model structure. The main part is taken by the simulation results and their analysis, where the comparison between different models of technical change as well as different decision rules is made. The concluding section contains some brief discussion of results.

\section{Model}

We introduce the model of endogenous technical change in this section. First, we model undirected technical change by allowing for the productivity parameter, $A(t)$, to be controlled by the agent, while leaving the emissions reduction technology, $e(t)$, exogenous which, later on, is controlled by the agent, too. The model presented below may be viewed as a straightforward extension of the model with exogenous 
technical change by Bréchet et al. [5]. We take this model with exogenous technical change as the benchmark.

\subsection{Undirected Endogenous Technical Change}

Consider first the model with only productivity being controlled by the agent. There is also a gradual process of reduction of emissions intensity, which is assumed to be exogenous for the time being. The agent in the model represents some central authority (government). This agent has full information about the influence of economic activities on the environment. The economic part of the model is rather stylized and represented by the capital accumulation process. The climate change is represented by a pair of equations for the dynamics of temperature and greenhouse gas (GHG) concentrations.

The agent optimally chooses the rate of consumption per capita and the rate of abatement activities to maximize social welfare and keep environmental degradation limited. The agent can also increase the productivity of the economy through R\&D investments. With these assumptions the control problem of the agent contains 4 state variables (capital, temperature, GHG concentration and the state of technology) and 3 control variables (consumption rate, abatement rate and R\&D investments per capita):

$$
\begin{array}{r}
J^{E}=\max _{u, a, g}\left\{\int_{0}^{T} \mathrm{e}^{-r t}\left[\frac{[u(t) Y(t)]^{1-\gamma}}{1-\gamma}\right] d t\right\} \\
\dot{k}(t)=-\delta k(t)+\left[1-u(t)-c_{1}(a(t))-c_{1}(g(t))\right] Y(t) ; \\
\dot{\tau}(t)=-\lambda \tau(t)+d(m(t))=-\lambda \tau(t)+\eta \ln \frac{m}{m_{0}^{*}} ; \\
\dot{m}(t)=-v m(t)+(1-a(t)) e(t) Y(t) ; \\
\dot{x}(t)=\beta g(t)-\delta_{2} x(t) ; \\
Y(t)=A^{E}(t) \phi(\tau(t)) k(t)^{\alpha}=A^{E}(t)\left(\frac{1}{1+\theta_{1} \tau^{\theta_{2}}}\right) k(t)^{\alpha} ; \\
A^{E}(t)=1+\omega x(t) .
\end{array}
$$

where:

$J^{E}$ is the objective functional;

$r$ is the discount rate;

$u(t)$ is the consumption rate per capita;

$Y(t)$ is the total output; 
$k(t)$ is the total capital;

$\delta$ is the depreciation rate of capital;

$a(t)$ is the abatement rate;

$g(t)$ are R\&D investments;

$\tau(t)$ is the temperature increase from the preindustrial level;

$\lambda$ is the rate of temperature decrease due to natural causes;

$m(t)$ is the GHG concentration in the world's atmosphere;

$v$ is the rate of recovery of the atmosphere due to natural absorption;

$e(t)$ is the reduction of intensity of emissions from economic activities; $x(t)$ is the state of technology;

$A^{E}(t)$ is the productivity of the economy;

$\phi(\tau(t))$ is the damage function depending from the temperature increase;

$\alpha$ is the parameter of capital productivity;

$\omega$ is the rate of transformation of the current state of technology into the productivity of the economy.

In the model the evolution of state variables is given in the following way:

- Capital increases due to investments into capital, Eq. (2);

- Temperature increases as a function of the GHG concentration in the atmosphere, Eq. (3);

- GHG concentration increases due to economic activity in the economy (it is assumed that natural causes may be neglected), while the impact of economic activity is weakened through abatement and exogenous improvement in cleaning technologies, Eq. (4);

- Technology improves in a linear way from R\&D investments while decreasing in the absence of such investments, Eq. (5);

- Output is of Cobb-Douglas type with labour supply normalized to unity with no population growth, Eq. (6);

- At last, productivity grows due to the transmission of a (fixed) proportion of technology into the production technology, Eq. (7).

It has to be noted that the original model of Bréchet et al. [5] is easily obtained from this model by assuming a constant and linear increase in productivity, i.e. by substituting Eq. (7) with the linear technology $A^{B}=\kappa_{1} t+\kappa_{2}$ and by setting $e(t)=\mathbf{e}^{-l_{1} t-l_{2}}$ as well as dropping the Eq. (5) and the term $c_{1}(g(t))$ from Eq. (2).

The form of dynamics of technical progress itself is rather simple: the technology improves via the investments into the technological progress, $g(t)$ and declines in the absence of investments with some rate $\delta_{2}$. Such a form of dynamics is rather simple and yet allows for the existence of steady state and endogenous technology.

In the case of (undirected) endogenous technical change we assume the same cost function for technology investments and for abatement $a(t)$ :

$$
\begin{aligned}
& c_{1}(g(t))=0.01 \frac{g(t)}{1-g(t)} ; \\
& c_{1}(a(t))=0.01 \frac{a(t)}{1-a(t)} .
\end{aligned}
$$


This specification guarantees that there will be some resources left for consumption with any positive values of abatement and R\&D investments. However, negative investments into the capital are possible: in this case capital decreases in time.

Making use of this specification of cost functions, we write down the analytic form of optimal controls for the problem given by Eq. (1) s.t. Eqs. (2)-(7):

$$
\begin{array}{r}
u_{o p t}^{E}=\frac{\psi_{k}(t)^{-\frac{1}{\gamma}} k(t)^{-\alpha}}{\frac{1}{1+\theta_{1} \tau(t)^{\theta_{2}}}(1+\omega x(t))} ; \\
a_{o p t}^{E}(t)=1-0.1 \frac{\sqrt{-\exp \left(l_{1} t+l_{2}\right) \psi_{m}(t) \psi_{k}(t)}}{\psi_{m}(t)} ; \\
g_{\text {opt }}^{E}(t)=1-0.1 \frac{\sqrt{\beta_{1} \frac{1}{1+\theta_{1} \tau(t)^{\theta_{2}}}(1+\omega x(t)) \psi_{x}(t) \psi_{k}(t) k^{\alpha}(t)}}{\beta_{1} \psi_{x}(t)} .
\end{array}
$$

It can be seen that the optimal abatement rate depends only on the ratio of shadow costs of capital and environmental degradation (which coincides with the benchmark model), but the consumption rate now negatively depends on technical progress that is endogenous. This means that technology boosting the total output, makes consumption higher even with the same share of output being devoted to consumption and, thus, the faster is the technological change, the lower this consumption share has to be. Investments into technology depend on the level of technology achieved, on the capital level and on the ratio of shadow costs of capital and technology. The resulting dynamical system for the state variables is 4-dimensional and explicitly includes technical progress:

$$
\begin{array}{r}
\dot{k}(t)=-\delta k(t)+\left[1-u_{o p t}^{E}(t)-0.01 \frac{a_{o p t}^{E}(t)}{1-a_{o p t}^{E}(t)}-0.01 \frac{x_{o p t}^{E}(t)}{1-x_{o p t}^{E}(t)}\right] \\
\cdot(1+\omega x(t)) \frac{1}{1+\theta_{1} \tau^{\theta_{2}}} k(t)^{\alpha} ; \\
\dot{\tau}(t)=-\lambda \tau(t)+\eta \ln \frac{m}{m_{0}^{*}} ; \\
\dot{m}(t)=-v m(t)+\left(1-a_{o p t}^{E}(t)\right) \exp \left(\iota_{1} t+\iota_{2}\right)(1+\omega x(t)) \frac{1}{1+\theta_{1} \tau^{\theta_{2}}} k(t)^{\alpha} ; \\
\dot{x}(t)=\beta_{1} g_{o p t}^{E}(t)-\beta_{2} x(t) .
\end{array}
$$

where $u_{o p t}^{E}(t), a_{\text {opt }}^{E}(t), g_{\text {opt }}^{E}(t)$ are given by Eqs. (9).

The main difference in this system compared to that of the model with exogenous technical change comes from the endogenous technology which increases productivity by the factor $\omega$ and which is governed by technological investments, rather than by the exogenous growth rate. In such a system emissions of GHGs depend not only on the capital accumulation but also on technological advances in the econ- 
omy which creates a link between the technological and the environmental sector. However, the abatement rate does not depend on technology and is exactly the same as in the benchmark model. Thus, the model becomes of an endogenous growth type, where the growth rates are defined through technological change. This technological change, however, is described in rather a stylized way and does not take into account the impact of technology on the reduction of emissions intensity, $e(t)$. This is achieved by further extending the basic model to account for the direction of technological change.

\subsection{Directed Endogenous Technical Change}

To model directed technical change we relax the assumption of the exogenous rate of emissions intensity decrease, $e(t)$. Now, we allow this to depend on the endogenous technological development, too. To this end, we assume that a certain fraction of technological progress is devoted to the reduction of emissions intensity without increasing productivity, while the other fraction is devoted to the increase in productivity without reducing emissions. We respecify the functions $e(t), A(t)$ as follows:

$$
\begin{gathered}
e^{D}(t)=\frac{e_{0}}{1+(1-\varepsilon) \omega x(t)} ; \\
A^{D}(t)=1+\varepsilon \omega x(t) .
\end{gathered}
$$

and the dynamic problem is formulated with the same constraints as in Eqs. (1). The parameter $e_{0}$ is set to the initial level of the emissions intensity from the benchmark model, $e_{0}=e(0)$. In such a formulation, the (exogenous) parameter $\varepsilon \in[0, \ldots, 1]$ measures the direction of technical progress. With $\varepsilon=0$ all of the technical progress is devoted to the reduction of emissions from production without increasing productivity at all, while with $\varepsilon=1$ all of the technical progress is going to the increase in productivity. Parameter $\omega$, as before, is measuring the efficiency of technical progress for productivity increase.

The optimal controls in this case are:

$$
\begin{array}{r}
u_{o p t}^{D}=\frac{\psi_{k}(t)^{-\frac{1}{\gamma}} k(t)^{-\alpha}}{\frac{1}{1+\theta_{1} \tau(t)^{\theta_{2}}}(1+\varepsilon \omega x(t))} ; \\
a_{o p t}^{D}(t)=1-0.1 \frac{\sqrt{-\frac{e_{0}}{1+(1-\varepsilon) \omega x(t)} \psi_{m}(t) \psi_{k}(t)}}{\psi_{m}(t)} ; \\
g_{o p t}^{D}(t)=1-0.1 \frac{\sqrt{\beta_{1 \frac{1}{1+\theta_{1} \tau(t)^{\theta_{2}}}}(1+\varepsilon \omega x(t)) \psi_{x}(t) \psi_{k}(t) k^{\alpha}(t)}}{\beta_{1} \psi_{x}(t)} .
\end{array}
$$

It can be seen that for the case of directed technical change, the abatement rates are different from the benchmark model as well as from undirected endogenous 
progress and include the evolution of technology as an argument. This links abatement efforts to technology, whereas in the undirected version of the model such a link is absent and technology influences the environment only through productivity increases in a negative way. In this case, the dynamical system for state variables changes and emissions accumulation depends on technical progress in an ambiguous way: it may decrease due to the evolution of clean technology or increase because of higher productivity and more production. The exact direction depends on the parameter $\varepsilon$ :

$$
\begin{array}{r}
\dot{k}(t)=-\delta k(t)+\left[1-u_{o p t}^{D}(t)-0.01 \frac{a_{o p t}^{D}(t)}{1-a_{o p t}^{D}(t)}-0.01 \frac{x_{o p t}^{E}(t)}{1-x_{o p t}^{E}(t)}\right] \\
\cdot(1+\varepsilon \omega x(t)) \frac{1}{1+\theta_{1} \tau^{\theta_{2}}} k(t)^{\alpha} ; \\
\dot{\tau}(t)=-\lambda \tau(t)+\eta \ln \frac{m}{m_{0}^{*}} ; \\
\dot{m}(t)=-v m(t)+\left(1-a_{o p t}^{D}(t)\right) \frac{e_{0}(1+\varepsilon \omega x(t))}{1+(1-\varepsilon) \omega x(t)} \frac{1}{1+\theta_{1} \tau^{\theta_{2}}} k(t)^{\alpha} ; \\
\dot{x}(t)=\beta_{1} g_{o p t}^{D}(t)-\beta_{2} x(t) ;
\end{array}
$$

where $u_{\text {opt }}^{D}(t), a_{\text {opt }}^{D}(t), g_{\text {opt }}^{D}(t)$ are given by Eqs. (12). For the case $\varepsilon=0.5$ technical progress is environmentally neutral as the term $\frac{(1+\varepsilon \omega x(t))}{1+(1-\varepsilon) \omega x(t)}$ cancels out from the emissions equation. In this case, technology influences only the productivity growth, but productivity growth does not influence the environment, as its negative externality is exactly counterbalanced by the reduction in emissions intensity from the clean technology. In all other cases, the technology is not neutral and influences emissions negatively or positively.

\subsection{Informational Regimes of the Economy}

The main focus of this paper is in the comparison of the dynamics of the environment and the economy under different informational regimes. Both versions of the model presented above assume that the agent possesses full information about the links between economic and technological activities and the environment. The alternative informational structure assumes an informationally constrained agent who does not continuously observe the influence of his/her activities on the environment. Instead, he/she maximizes welfare over a certain period of time neglecting the environment. After the period has elapsed, he/she observes the state of the environment and its effect on output and solves a new optimization problem, again over a certain period of time neglecting environmental concerns. To model such an information- 
ally constrained economy, we make use of the non-linear model predictive control (NMPC) technique.

In the modern world, agents should be aware of the changing environment. However, real-time online measurement of the state of the environment is costly and hence such a measurement might be made at some regular periods of time. Another argument for economic intuition might be that economic processes have much higher speed than environmental ones and the central authority in the economy may assume the state of environment to be constant for some periods.

With the help of the NMPC technique one may model such infrequent observations of the state of the environment. To this end, assume that the agent under consideration is measuring the state of environment every $k$ periods of time and revises his/her optimal controls over consumption, abatement and technology investments. In such a case one has to consider the full dynamical system given by Eqs. (1) for true state dynamics and the reduced one for the determination of optimal controls of the agent under informational constraints of this type.

Following the idea of Bréchet et al. [5], we define strategies of the informationally constrained agent as Business-as-Usual (BaU) scenarios in the following way:

1. At the initial point in time, $t_{0}$, an agent is solving the reduced dynamical problem (defined in the Appendix) on some fixed time horizon $\Theta$ (with $\Theta$ being some long but finite time horizon being chosen in such a way, as this length allows the system to be marginally close to the steady state) and defines his/her optimal controls;

2. These controls are then used to determine the evolution of the full dynamical system which includes environmental variables as well as economic ones for the same time horizon;

3. After $h=t_{h}-t_{0}$ time (being the step of measurement of the environment) an agent measures the state of the full system at the time $t=t_{h}$ and revises his/her optimal controls with this state of the system given as an initial state from $t=t_{h}$ onwards till $t=t_{h}+\Theta$ (thus obtaining the new optimal policy for the whole planning horizon and not just till the next measurement time);

4. When the next measurement time $t_{h+1}$ is reached, the agent again revises his/her policies in the view of new information obtained about the state of the environment;

5. The procedure repeats until the terminal time is reached.

Note that such a procedure essentially requires a limited time horizon for the agent since, otherwise, it could not be completed in a finite number of steps. This difficulty is resolved by choosing rather a long terminal time $\theta$, as the system may arrive to its steady state within this time length. ${ }^{2}$

\footnotetext{
${ }^{2}$ See the Appendix for an illustration of NMPC for the model with directed technical change.
} 


\section{Numerical Simulation}

\subsection{Computational Issues and Calibration}

To obtain solutions for all of the versions of the model we make use of the gradient projection method of simulations. The basic idea is as follows: at each simulation step the vector of optimal controls is computed iteratively as the preceding value plus the gradient increase. As the control approaches the optimal value, the gradient decreases. At the optimal point the gradient of the system is zero. In practice, iterations are performed until the gradient reaches a sufficiently small value. The steps of the algorithm of iterations is described below.

1. Set initial values for controls $u^{0}, a^{0}, g^{0}$;

2. Solve the system for state variables, one of Eqs. (10), (13), depending on the version of the model;

3. Calculated state variables $k^{0}, m^{0}, \tau^{0}, x^{0}$ are used for solution of the co-state system;

4. Solutions of both systems are used to compute the next-step gradient of the system, $\nabla \mathbf{X}^{1}$

5. Next step controls have the form $u^{1}=u^{0}+b \cdot \nabla \mathbf{X}^{1}$;

6. The procedure repeats until $\nabla \mathbf{X}^{k} \rightarrow 0$.

The gradient of the system is given by first-order conditions for controls, Eqs. (15), (18) or (19), depending on the model under consideration. The $b$ parameter is chosen arbitrarily and is the scale of one iteration step, remaining constant for all iterations, but varying from system to system. This is determined experimentally and depends on the numeric scale of the gradient being computed.

Note that the algorithm above is valid only for the computation of solutions under full information, while for implementing the NMPC technique for informationally constrained economies it is not sufficient. In the latter case, the procedure above has to be repeated at each time step, $t_{i}$, along the whole time path. Otherwise, the algorithm remains the same. The values of the parameters $\omega$ and $\varepsilon$ depend on the respective scenario under consideration and are explained below. As concerns the other parameters, these are the same for all different scenarios and for the calibration we set the parameters to the values given in Table 1 .

Concerning the evolution of technology, we consider different scenarios with respect to the choice of exogenously given transformation rate $\omega$ and the proportions of clean and dirty technologies $\varepsilon$. These scenarios are summarized in Table 2.

Here, the upper part gives values of the transformation rate $\omega$ being considered in simulations for endogenous undirected technical change. Since the technology is transformed only in productivity increase, this is equivalent to setting the $\varepsilon$ parameter to 1 , as the table shows. The lower part of the table shows how different proportions of technical change, going into cleaning or more productive technologies, affect the resulting effective transformation rate, $\varepsilon \omega$, and the fraction of technical change in cleaner technologies, $(1-\varepsilon) \omega$. Setting $\varepsilon=0.5$ implies environ- 
Table 1: Parameter values

\begin{tabular}{lcc}
\hline Economic parameters & & \\
\hline Depreciation rate & $\delta$ & 0.075 \\
Inverse of elasticity of substitution & $\gamma$ & 2 \\
Interest rate & $r$ & 0.015 \\
Capital elasticity & $\alpha$ & 0.45 \\
\hline Climate parameters & & \\
\hline Temperature re-absorption & $\lambda$ & 0.11 \\
Climate sensitivity & $\eta$ & 0.59 \\
Pre-industrial carbon concentration & $m_{0}^{*}$ & 5.964 \\
Damage function parameter 1 & $\theta_{1}$ & 0.0057 \\
Damage function parameter 2 & $\theta_{2}$ & 2 \\
GHG re-absorption rate & $v$ & 0.0054 \\
\hline Technological parameters & & \\
\hline Emissions intensity reduction parameter 1 & & \\
Emissions intensity reduction parameter 2 & $l_{1}$ & 0.00384 \\
Initial emissions intensity reduction for endogenous models & $e_{0}$ & 3.1535 \\
Linear technology parameter 1 & 0.0427 \\
Linear technology parameter 2 & $\kappa_{1}$ & 1 \\
Efficiency of technological investments & $\kappa_{2}$ & 0.0014 \\
Decay of technology in absence of investments & $\beta_{1}$ & 0.7 \\
& $\beta_{2}$ & 0.1 \\
\hline & & \\
\hline
\end{tabular}

Table 2: Simulated technological parameters values

\begin{tabular}{lccccc} 
Scenario & $\omega$ & $\varepsilon$ & $\omega \varepsilon$ & $(1-\varepsilon) \omega$ \\
\hline Undirected change & & & & \\
Slow growth & 0.05 & 1 & 0.05 & 0 \\
Normal growth & 0.10 & 1 & 0.10 & 0 \\
\hline Directed change & & & & \\
Clean growth & 0.20 & 0.1 & 0.02 & 0.18 \\
Neutral growth & 0.20 & 0.5 & 0.1 & 0.1 \\
Dirty growth & 0.20 & 0.9 & 0.18 & 0.02 \\
\hline \hline
\end{tabular}

mentally neutral technical change. With a productivity impact of $\omega=0.2$ this yields the same overall productivity growth as for the undirected change $(\varepsilon \cdot \omega=0.1)$. Next, we consider the "green" or "clean growth" scenario, where the technological progress is biased towards the reduction of emissions intensity, with $\varepsilon=0.1$. In such a case, overall productivity growth is much slower than for the undirected technical change, $\varepsilon \cdot \omega=0.02$, while emissions intensity reduces with the factor $1 /((1+(1-\varepsilon) \cdot \omega))=0.84$ from the initial state of cleaning technology $e(0)$. Finally, we consider the "dirty growth" scenario with $\varepsilon=0.9$ and the resulting productivity growth $\varepsilon \cdot \omega=0.18$ higher than for undirected change and higher emissions intensity with only slight reduction to 0.98 level in 100 years. 


\subsection{Discussion of the Damage Function}

Here we discuss our choice of parameters of the damage function, $\theta_{1}, \theta_{2}$. With the chosen functional form of this function, given by Eq. (8), the parameter $\theta_{1}$ measures the linear impact of the temperature on the productivity of capital, while $\theta_{2}$ is chosen due to the functional form considerations to provide a hyperbolic type decay rate for productivity with temperature increases. This specification follows the one assumed in the paper by Bréchet [5]: an increase in the mean temperature by $2^{\circ} \mathrm{C}$ leads to a $2.23 \%$ decrease in productivity. However this effect is not linear but rises: the higher increase in temperature leads to even stronger decreases in productivity, as Table 3 shows.

It can be seen that the worst case scenario leads to an extreme rise in temperature

Table 3: Damage function

\begin{tabular}{cc}
\hline Temperature increase Decrease in productivity \\
\hline$+2^{\circ} \mathrm{C}$ & $-2.23 \%$ \\
$+4^{\circ} \mathrm{C}$ & $-8.36 \%$ \\
$+6^{\circ} \mathrm{C}$ & $-17.02 \%$ \\
$+8^{\circ} \mathrm{C}$ & $-26.73 \%$ \\
\hline
\end{tabular}

of $8^{\circ} \mathrm{C}$ and implies a reduction of productivity by more than $25 \%$. At the same time, the chosen specification of exogenous productivity growth in the benchmark model implies an increase of productivity by the same $25 \%$ in 100 years. Thus, in the exogenous growth scenario the technology growth always has a higher significance than environmental damage, which is one reason for taking such a high damage function compared to Nordhaus [12], where the damage is almost twice as low for the same temperature increase: for a $2^{\circ} \mathrm{C}$ increase in temperature only a $1 \%$ decrease in productivity is assumed there. In the view of recent data, however, such an assumption appears too optimistic, since it does not account for the additional losses in GDP due to the impact of higher temperatures on the sea level increase, which has already started. With this in mind, it might be the case that more pessimistic estimates, as adopted here, might be useful. Our calibration is more in line with the calibration of damage functions for Europe as in the model by Hassler and Krusell [9], where it is claimed that environmental damages differ from region to region and appear to be higher for Africa and for the EU than for the U.S. or China. There, it is assumed that a $2{ }^{\circ} \mathrm{C}$ increase leads to a $2.83 \%$ productivity damage for Europe and to $3.91 \%$ damages for Africa. Hence, our calibration values are in between the values used in the two papers above mentioned. 


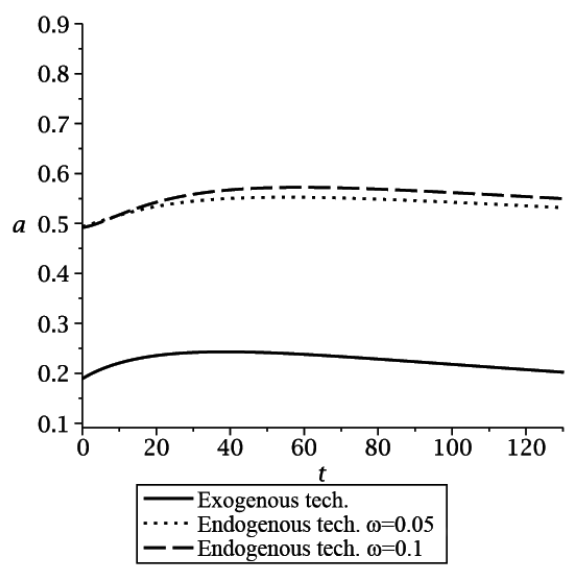

(a) Abatement rates

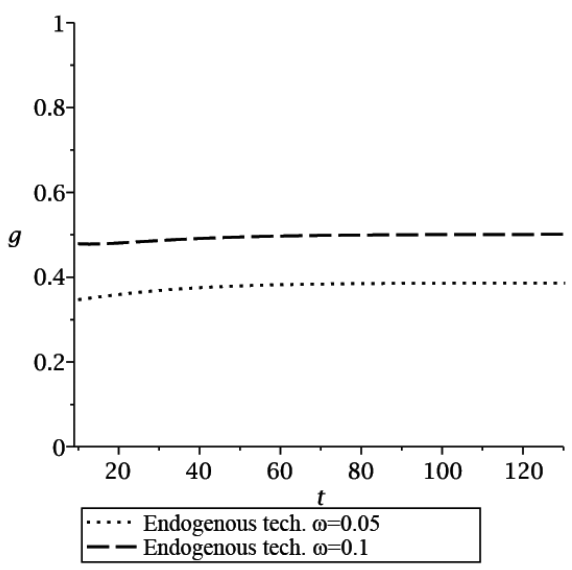

(b) R\&D investments

Fig. 1: Optimal policies for the exogenous and endogenous technology

\subsection{Economy with Full Information}

\section{Exogenous vs. Undirected Endogenous Technology}

The introduction of the endogenous technology into the benchmark model, described by Eqs. (1)-(7), allows for more efficient environmental policy of the agent in the case of full information. However, the efficiency of technological progress in respect of increasing productivity plays a crucial role for social welfare in terms of consumption. We consider two values for this parameter, which give the productivity growth lower and higher than the exogenous linear growth in the benchmark model. Namely, we take $\omega=0.05$ for low yield of technology for productivity growth and $\omega=0.1$ for high yield.

First, consider the dynamics of optimal abatement and technology investments per capita in Figure 1. One can see that abatement efforts are higher for both scenarios and the difference between low and high technology yields is rather small. Both are stabilized at the level between 0.5 and 0.6 , while in the exogenous technology case it is much lower, at the level of 0.2. This differs from the dynamics of 


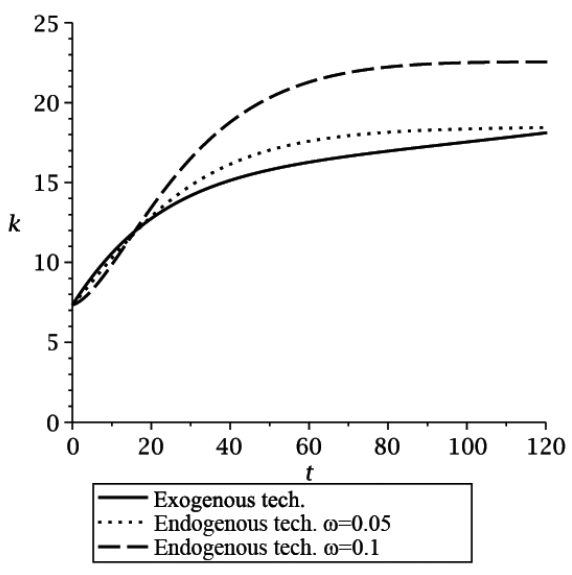

(a) Capital dynamics

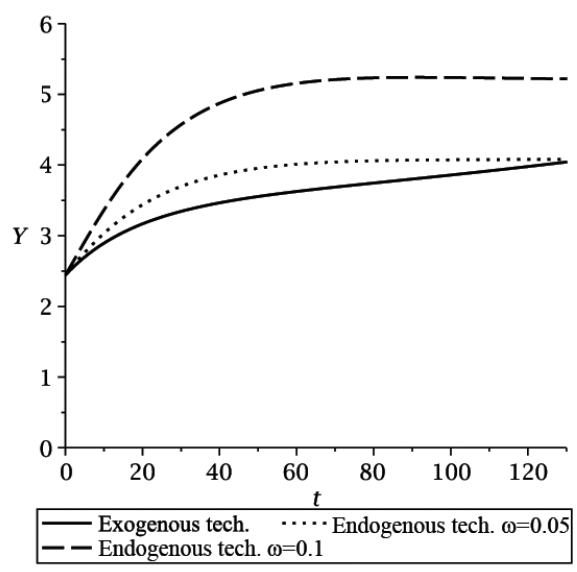

(b) Output dynamics

Fig. 2: Economic dynamics for the basic model and with endogenous technology

the benchmark model in [5] substantially due to different values of parameters. One would expect higher abatement efforts for higher technology impact. It is indeed so, since abatement efforts at Figure 1a are given in per capita terms. In terms of final output these investments are higher for the high technology yield scenario, since the output itself is higher.

Technology investments in both endogenous technology scenarios are also almost constant in time with more investments being made for the higher omega parameter. There are more incentives to invest into technology if it has more impact on productivity, thus higher output share is invested.

Because of the reduced consumption share due to endogenous technology (see Figure 5a), capital accumulation is boosted in comparison to the benchmark model as well as the total output of the economy. Furthermore, in the scenario with low impact of technology on productivity capital accumulation rates at later stages of development decline and are outperformed by the linearly rising exogenous technology of the basic model. The same is true for the output. This can be seen in Figure 2.

This figure demonstrates the importance of parameter $\omega$ for the economy. 


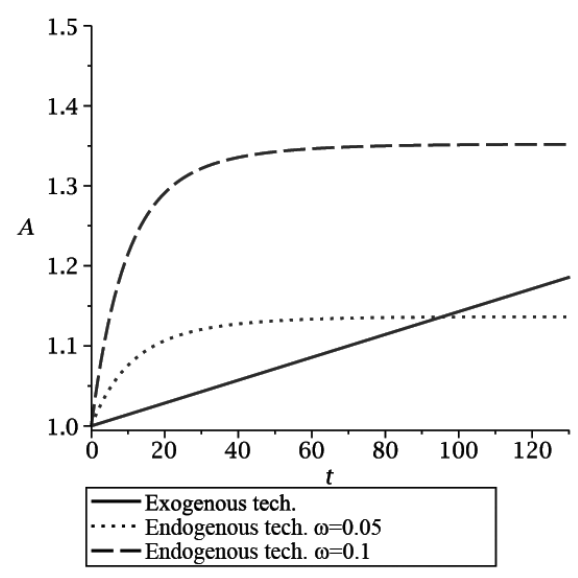

Fig. 3: Productivity for the basic model and with endogenous technology

With high efficiency of the transformation of technical change into the productivity growth, the growth of capital and output is stimulated by higher technological advances and by lower consumption shares, while for lower values of $\omega$ the reduction in consumption per se is not sufficient to outperform the exogenous technology. To see this, consider the relative productivity growth for all three scenarios in Figure 3.

As a result of lower consumption shares and higher abatement investments per capita, the climate in the endogenous technology version of the model demonstrates much less drastic temperature increases and GHG concentrations than the benchmark model as Figure 4 shows.

It should be noted that after 120 years of simulation, the model with endogenous technology tends to the stabilization of temperature and emissions at some lower level compared to the model with exogenous technical change. In particular, with slower advances in productivity $(\omega=0.05)$ the temperature increase amounts to not more than $2^{\circ} \mathrm{C}$, while for the benchmark model with exogenous technology this value is higher than $3.5^{\circ} \mathrm{C}$ and approaches $4^{\circ} \mathrm{C}$. Slower environmental degradation together with higher economic performance of the endogenous technology model are the consequences of different dynamics of technical change in comparison with the linear one in the benchmark model. The highest increase of productivity happens in the first 20 years of simulation, while later on $R \& D$ investments are being made 


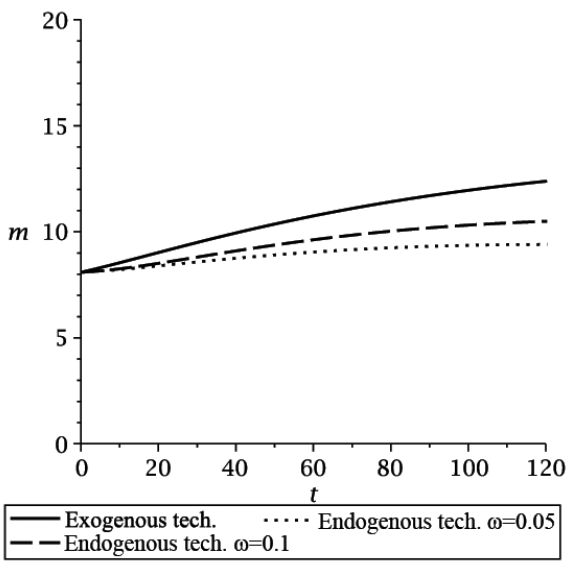

(a) GHG concentration

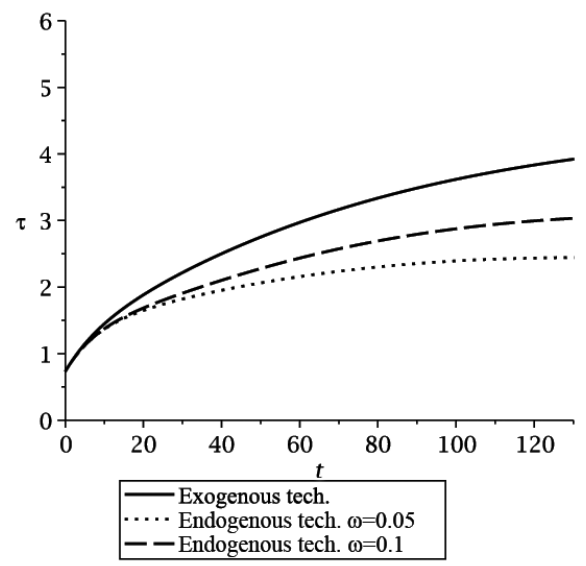

(b) Temperature increase

Fig. 4: Climate dynamics for the basic model and with endogenous technology

on the level just to support the achieved productivity level. In such a way the impact of technology on the environment is minimized and the environmental degradation slows down. Additional resources which are gained through this rapid technological advance are then devoted mainly to abatement activities further reducing the impact of the output on the environment. Thus, under endogenous technological change it appears to be optimal for the fully informed agent to "grow up first and clean up later", rather then gradually increase his/her productivity and invest into the abatements simultaneously. As a result, the environment suffers less, since abatement activities are initially and all over the simulation period higher than in the scenario with exogenous technology.

In terms of consumption and welfare, the scenario with a high impact of technology on productivity delivers greater consumption to the representative consumer than the benchmark scenario, while this is not true for the low impact scenario. This is demonstrated in Figure 5.

At last, we compute welfare gains or losses expressed as relative changes of present value consumption. To be precise, we compute the present value of the necessary change in the consumption stream (in percent) that makes welfare in the sce- 


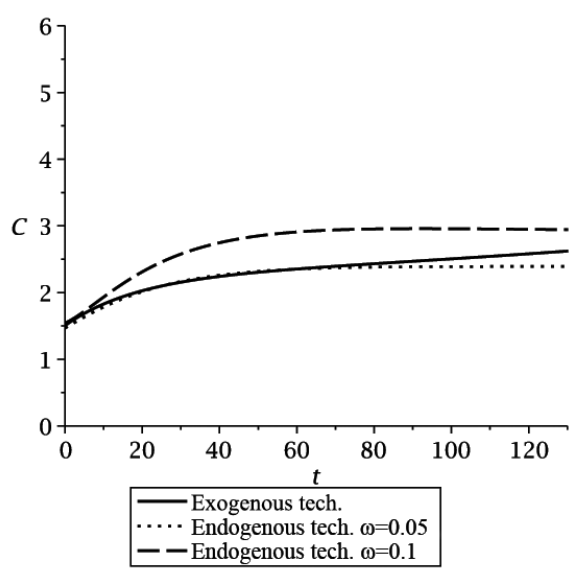

Fig. 5: Consumption dynamics for the basic model and with endogenous technology

nario with exogenous technology equal to welfare in the scenario with endogenous technology. The results over 50 and 100 years of simulations are shown in Table 4. The planning horizon for the agent is the same for all the scenarios and equals 180 years. Thus we compare present value consumption changes along the same optimal trajectory in two different time points.

Table 4: Present value consumption changes with endogenous technology (relative to exogenous)

\begin{tabular}{rrr}
\hline$\omega$ & $t=50$ & $t=100$ \\
\hline 0.05 & $-0.96 \%$ & $-0.80 \%$ \\
0.1 & $13.78 \%$ & $17.27 \%$ \\
\hline
\end{tabular}

For longer time horizons the model with exogenous technology outperforms the model with endogenous technology with low impact $(\omega=0.05)$ in terms of consumption. The scenario with higher technology impact yields a much higher consumption path, increasing to more than 17 percent in 100 years above the benchmark 
model. For shorter time horizons, this difference is less drastic with an almost 14 percent increase in consumption in the case of endogenous technology with a high transformation rate. It should be noted, that these differences may be explained by the different assumptions on the form of technical change. In our endogenous technology model, technical change has an exponential form, while in the benchmark model it is linear. However, these simulations demonstrate, that exponential-type technical change is better for environment and for consumption if the agent controls technical change.

\section{Directed vs. Undirected Endogenous Technological Change}

Next we consider the extension of the model to the case of directed endogenous technical change. To this end we introduce the parameter of the direction of technical change through $\varepsilon$. We consider 3 different scenarios and compare them with the endogenous undirected change, discussed above, with a productivity impact of $\omega=0.1$, since this is the value which allows for productivity growth comparable to the exogenous one and is the "medium" scenario with the respect to economic and environmental dynamics. All the configurations of technological parameters are given in the Table 2.

Consider abatement and investments into technology in per capita terms displayed in Figure 6. The first thing to note is that abatement activities are increased for all scenarios of directed technical change in comparison with the undirected one. The highest abatement rate is obtained for the dirty growth scenario, while the lowest (among directed growth scenarios) for the clean growth. This seems rather intuitive: the higher productivity growth with dirty technology frees more resources for abatement activities, while with clean technology productivity grows much slower but, at the same time, the environmental damage is also lower such that abatement activities are not that necessary. However, in the case of undirected growth with comparable productivity, abatement rates are lower than for the neutral technical change which gives the same rate of productivity increase as the undirected change with $\omega=0.1$. This points to the difference between undirected and directed technical change models: with an exogenously given reduction of emissions, which is not part of the technical change managed by the agent, he/she has lower concerns for abatement activities even with a comparable productivity growth. Abatement rates dynamics is displayed at the Figure 6a.

The interesting difference can be observed for technology investments. These are also constant for all scenarios after 100 years. In the case of clean growth, technological investments are lower than for both scenarios of undirected growth, while they are higher for neutral and dirty growth. In these last two scenarios, technological investments are almost the same, although the return for such investments in terms of productivity is twice as high as for dirty growth. The economic intuition for this result may be as following. After achieving some sufficiently high productivity level, new additional resources are rather spent for abatement activities and consumption. It becomes more profitable, in terms of consumption gains, for the 


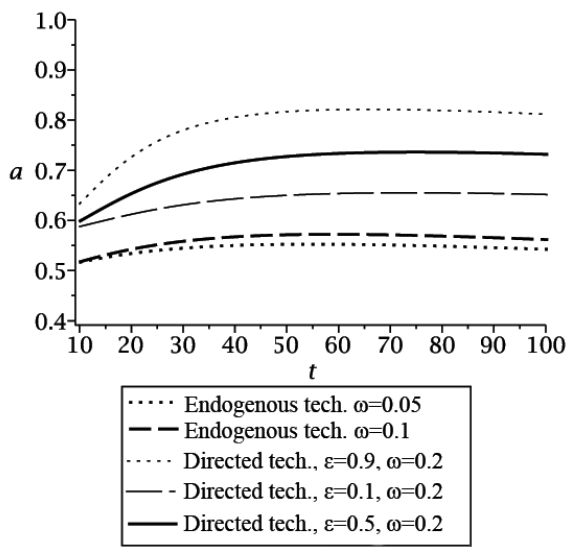

(a) Abatement rates

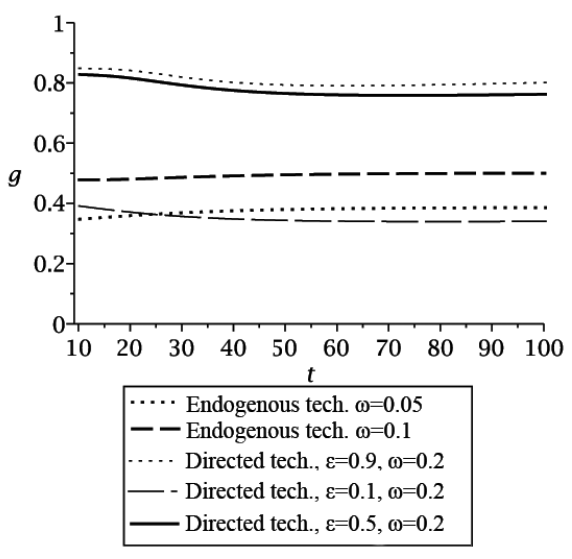

(b) R\&D investments rates

Fig. 6: Optimal controls with directed and undirected technical change

agent to invest additional resources into abatement to decrease damages, rather than to boost productivity further, since at the high level of productivity achieved, additional R\&D investments would increase productivity to rather a small extent. At the same time, additional abatements will significantly slow down the environmental degradation, thus, decreasing threats to the output and consumption coming from the $\phi(\tau)$ damage function. This also means that the threat of dirty technology is at least partially counterbalanced by reduced productivity growth (and the associated environmental threat) at later stages of development in the dirty growth scenario. $R \& D$ investments are displayed in Figure $6 b$.

The level of consumption is the lowest one for the clean growth scenario and the highest one with dirty growth. Undirected technical change, with technology impact $\omega=0.1$, yields lower consumption than the neutral directed growth scenario, which has the same overall impact of technology on productivity, $\varepsilon \omega=0.1$. The difference in steady state consumption levels between clean and dirty growth scenarios is almost $300 \%$. This is the direct consequence of lower capital accumulation and output for the clean growth scenario, since the productivity growth is much slower there. The dynamics of consumption is displayed in Figure 7. 


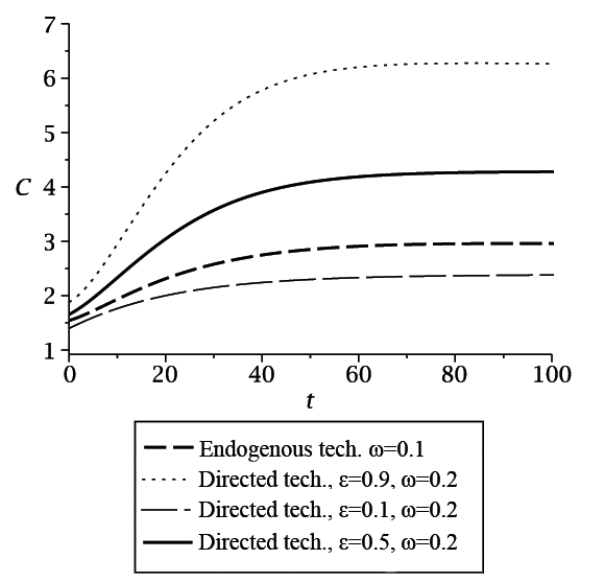

Fig. 7: Consumption with directed and undirected technical change

The dynamics of capital and output is displayed in Figure 8. One can observe that in the case of clean growth, capital accumulation and output of the economy are lower compared to undirected technical change, while these two are higher both for neutral and dirty growth scenarios. In all scenarios, the steady state levels of both variables are achieved after 100 years of simulations and remain constant afterwards. This is different from the benchmark model with exogenous technology because technology growth is not linear but rather of exponential type. Despite of almost equal technology investments in per capita terms for neutral and dirty scenarios, the capital and output dynamics in the latter case are higher by roughly 25 percent. This is the effect of higher productivity. Technology for the growth model with directed technical change is described by two variables rather than by one: emissions intensity reduction due to cleaner technology and productivity growth, displayed in Figure 9.

As it can be seen, productivity growth is higher in the case with directed technical change only for the dirty growth scenario, while directed technical change in the clean scenario generates smaller productivity growth than directed neutral and undirected technical progress. In the case of dirty growth, productivity grows twice in 100 years while in all other cases the growth is below 40 percent. This is the explanation why in the dirty growth case technology investments are the same as for the 


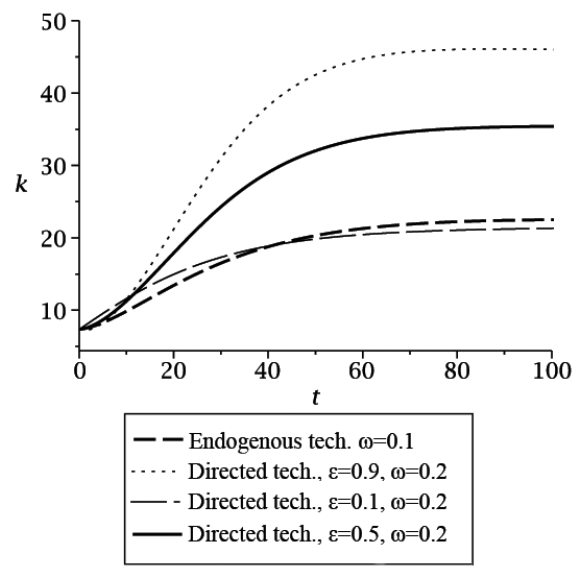

(a) Capital dynamics

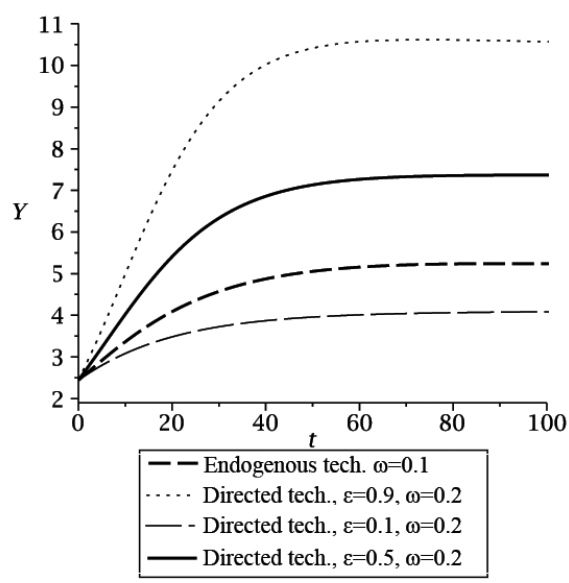

(b) Output dynamics

Fig. 8: Economic dynamics with directed and undirected technical change

neutral case: higher capital accumulation gives more investments in absolute value with the same share and still the productivity grows much faster. Emissions reduction for all directed growth scenarios is less intensive than for the exogenous function, even for the case of clean growth where 90 percent of technological progress is going into the emissions reduction. It is important to note that for the neutral case, the emissions reduction is not constant, as it is displayed on the graph, but the total influence of productivity growth plus emissions reduction technology is constant. One can conclude that the bias towards clean technology is not sufficient to achieve the same emissions reduction ratio as for the model with undirected technical change while losses in economic variables are substantial in comparison with dirty growth, as it is displayed in Figure 8.

At last, consider the dynamics of the environmental part of the model in Figure 10. One realizes that, in terms of environmental damages, the dirty growth scenario is very close to the undirected change, while the productivity is almost twice as high. At the same time neutral and clean growth scenarios provide a better environment but at the cost of economic losses. As a result, one may conclude that the dirty 


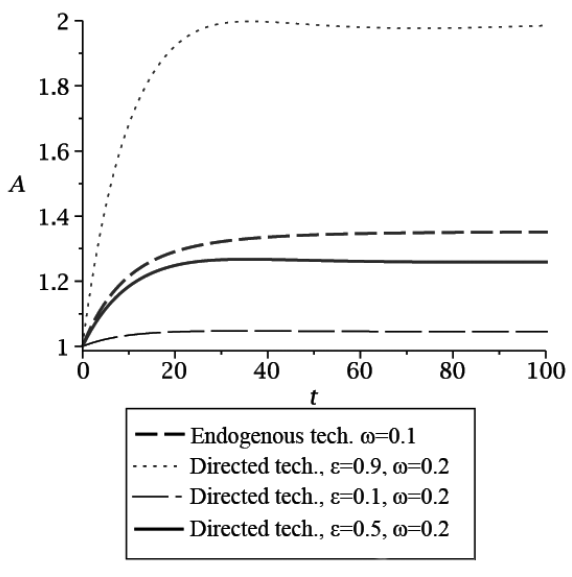

(a) Productivity growth

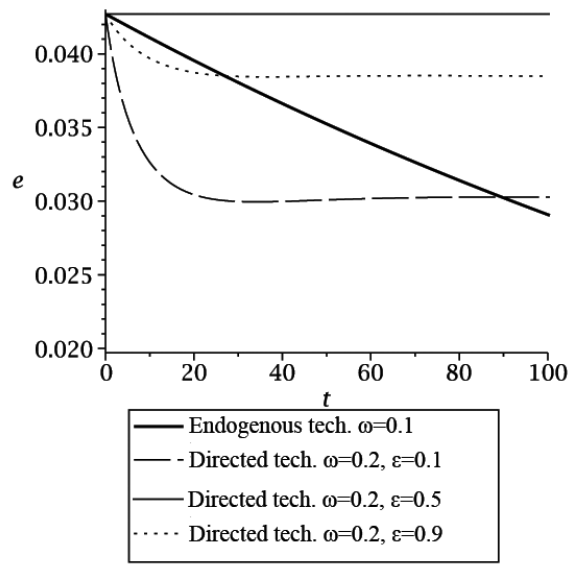

(b) Reduction in intensity of emissions

Fig. 9: Technology dynamics with directed and undirected technical change

growth scenario is the most beneficial for the economy by the total of economic and climate characteristics.

To obtain this aggregate measure, we compare welfare of the economy in the case of directed technical change with the undirected one, with welfare again expressed as percentage change of present value consumption. The change in present value consumption is calculated for a time period of 50 and 100 years as above. Changes are computed for directed technical change scenarios with $\omega=0.2$ relative to the undirected endogenous technical change model with $\omega=0.1$. Consumption changes are displayed in the Table 5.

One can see that the dirty growth scenario is by far the most beneficial one with an 80 percent rise in consumption in 50 years in comparison to the undirected change. The case of neutral technical progress also gives some improvement of roughly 30 percent. This happens due to lower environmental damages and higher economic dynamics in this scenario than for undirected change. The main drawback of the neutral technical progress is that it may happen only for exactly one value of the direction parameter, $\varepsilon$, and this is not easy to achieve in practical implementations of environmental policy. However, one may conclude, that if to choose 


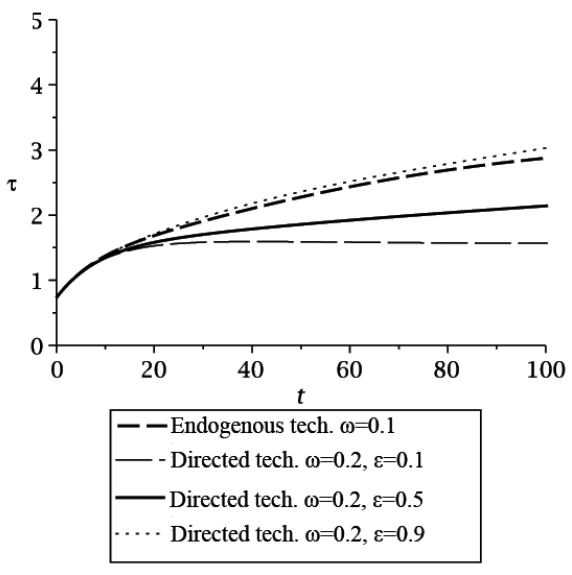

(a) Temperature increase

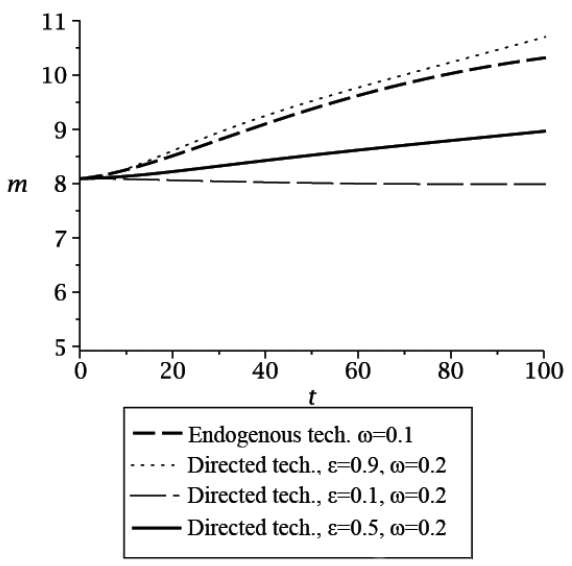

(b) GHG concentration

Fig. 10: Environmental dynamics with directed and undirected technical change

Table 5: Present value consumption changes with directed technical change (relative to undirected)

\begin{tabular}{ccc}
\hline$\varepsilon$ & $t=50$ & $t=100$ \\
\hline 0.1 (clean) & $-14.42 \%$ & $-17.16 \%$ \\
0.5 (neutral) & $28.63 \%$ & $29.98 \%$ \\
0.9 (dirty) & $79.17 \%$ & $84.35 \%$ \\
\hline
\end{tabular}

between clean and dirty technological scenarios, the dirtier is better, $\varepsilon \geq 0.5$, since the increase in productivity sets free resources for partial compensation of environmental damages through increases in abatement, rather than reduction in emissions intensity . 


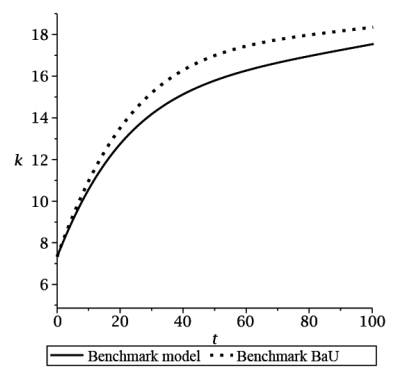

(a) Capital dynamics

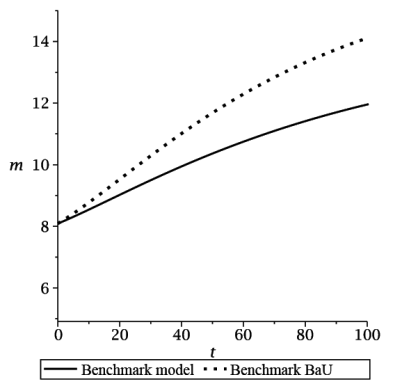

(b) GHG concentration

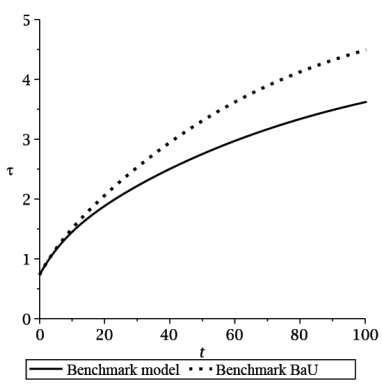

(c) Temperature increase

Fig. 11: BaU dynamics compared to full information (exogenous technology)

\subsection{Informationally Constrained Economy}

\section{Full information vs. Informationally-constrained Scenarios}

Here, we compare the simulation results for fully informed and informationally constrained $(\mathrm{BaU})$ behaviour of the agent. It turns out that in all cases, the environmental damages for $\mathrm{BaU}$ scenarios are higher than for the economy with full information. This is rather intuitive, since the main feature of the informationally constrained economy is the neglect of the influence of economic variables on the environment. The dynamics of the state variables in the benchmark model with exogenous technology under full information against the $\mathrm{BBaU}$ (basic $\mathrm{BaU}$ ) scenario are illustrated in Figure 11.

From this figure, it may be clearly seen that in the case of the BBaU scenario, GHG accumulation and the temperature increase are higher than for the benchmark model with full information whereas the capital stock is higher too. This is the typical feature for the majority of informationally constrained scenarios: higher environmental damages and higher capital growth. For the benchmark model with our set of parameters the general claim of the paper [5] holds: the informationally constrained economy yields lower consumption paths. However, the difference is very small. It amounts to a 0.68 percent decline in consumption in 50 years and to 1.12 percent decline in 100 years, in comparison with the full information scenario.

In the case of endogenous technology (EBaU), the difference is more drastic, since the agent neglects the influence of not only economic but also of technological variables on the environment. Technology influences the environment through 


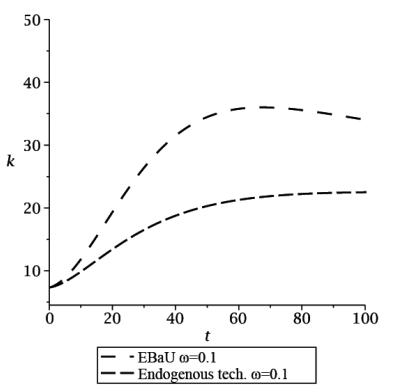

(a) Capital dynamics

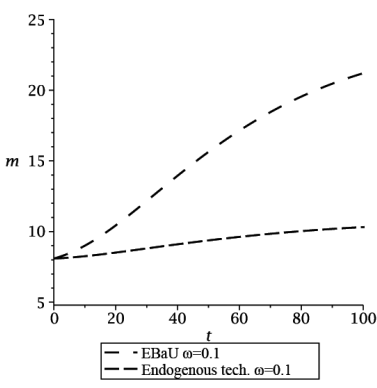

(b) GHG concentration

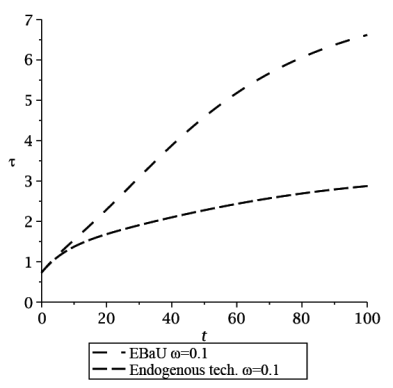

(c) Temperature increase

Fig. 12: BaU dynamics compared to full information (endogenous technology)

productivity growth which boosts the emissions accumulation, while the agent is unaware of this influence when determining his/her policy. As a result, the difference in dynamics between full information and informationally constrained scenarios is larger than for the exogenous model. This can be seen in Figure 12.

Even more differences between the two solutions are revealed for the case of directed technical change $(\mathrm{EDBaU})$, since now there is another additional influence of technology on the environment the $\mathrm{BaU}$ agent is unaware of: the emissions reduction intensity, $e(t)$, which is also endogenous in this version of the model. As a result, not only environmental damages are higher, as for undirected technical change, but the capital accumulation is lower for the EDBaU scenario than under the full information. This is seen in Figure 13 for the dirty growth scenario.

\section{Comparison of Different Technological Change Scenarios for the Informationally Constrained Economy}

Finally, we compare all of the computed scenarios with informational constraints with each other to find out possible gains and losses in social welfare as well as the dynamics of the economic-environmental system. First, consider the dynamics of technology investments for BaU systems in Figure 14.

Abatement rates are not controlled for in $\mathrm{BaU}$ scenarios since the agent is unaware of the dynamic link of economy and environment and thus cannot influence the degree of environmental damages. Technology investments are the highest for the $\mathrm{BaU}$ scenario with undirected endogenous technology ( $\mathrm{BBaU})$ (with $\omega=0.1$ ), 


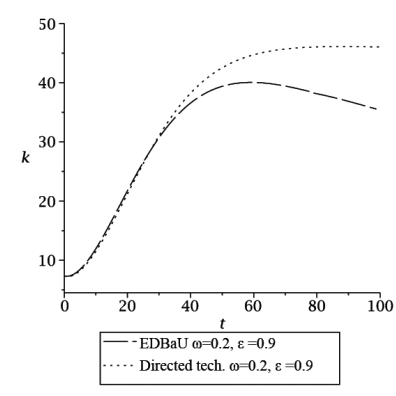

(a) Capital dynamics

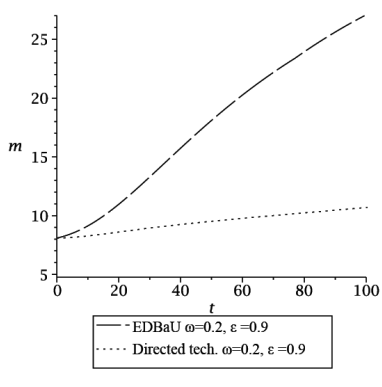

(b) GHG concentration

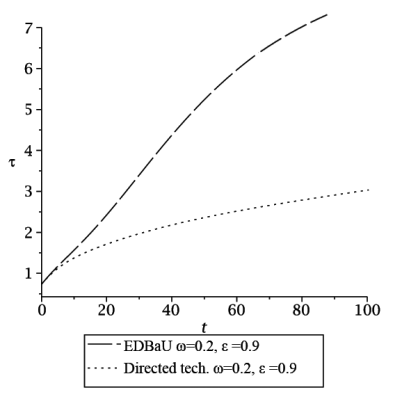

(c) Temperature increase

Fig. 13: BaU dynamics compared to full information (directed technical change)

while minimal for the clean growth $\mathrm{BaU}$ scenario with directed endogenous technology $(\mathrm{EDBaU})$ (with $\varepsilon \omega=0.02)$. Thus, one may conclude that the level of technology investments depends not only on the total productivity parameter ( $\omega$ and $\varepsilon \cdot \omega$ for $\mathrm{EBaU}$ and $\mathrm{EDBaU}$ scenarios, respectively), since this one is higher for the dirty growth scenario than for the EBaU scenario, but also on the achieved level of technology. There is a maximal level of technology which is sufficient for the agent and he/she does not continuously increase productivity, in the same way as for the full information scenarios above.

The economic dynamics of BaU scenarios is displayed in Figure 15. One may see that the dynamics of capital accumulation and output for the case of the clean growth $\mathrm{EDBaU}$ system is very close to the one of the $\mathrm{BBaU}$ scenario, while the consumption dynamics in general follows the same pattern as that of output. The ordering of consumption, output and capital accumulation paths is the same as for full information systems. Further, the capital accumulation for the EDBaU scenario is lower than for the full information directed growth case. In the case of undirected technical change, capital accumulation is higher for the EBaU scenario than for full information undirected growth. Thus, the difference between the dirty growth EDBaU scenario and EBaU is smaller than the difference between these scenarios under full information. To see that, just compare capital accumulation for $\mathrm{EBaU}$ and dirty EDBaU in Figure 15a and for their full information counterparts in Figure 8a.

Technology for $\mathrm{BaU}$ models is endogenous only for $\mathrm{EBaU}$ and $\mathrm{EDBaU}$ scenarios and its evolution is displayed in Figure 16. As it can be seen, productivity growth for EDBaU models may be lower or higher than for the EBaU model in the same way as for their optimal counterparts. In the clean growth scenario, only 2 percent of the 


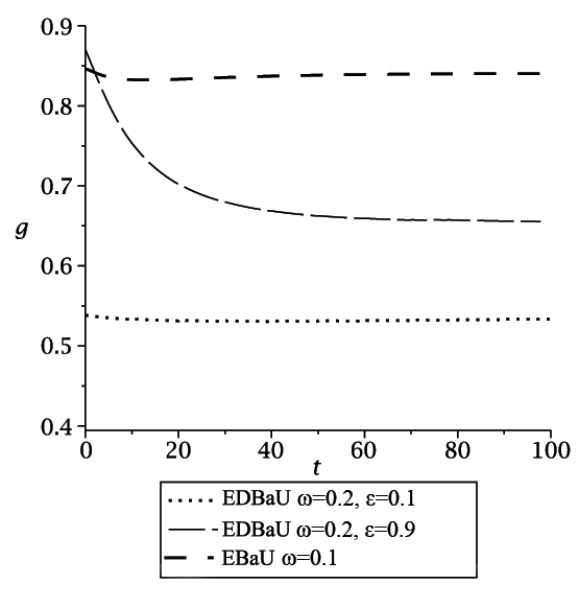

Fig. 14: Technology investments for BaU scenarios

total technical progress are going to the increase in productivity and the latter grows less than 10 percent in 100 years. With dirty growth, productivity grows almost twice which, however, is lower than for the optimal case since in the EDBaU scenario an agent overestimates the effect of technological investments for productivity. As a result, both capital accumulation as well as productivity growth are lower than in the full information case. On the other hand, productivity growth in the EBaU scenario is higher than for the full information strategy of undirected growth (roughly 50 percent against 30 percent) which leads to higher capital accumulation.

Such a difference appears because in the undirected growth case, the emissions reduction technology is exogenous and partially dissipates the effect of the productivity growth. As a result, the underestimation of the effect of technological investments by the agent in the EBaU scenario leads to lower capital accumulation and, consequently, to lower environmental damages compared to the EDBaU agent. In the latter case, emissions reduction intensity is rather low, especially for the dirty growth scenario in comparison to the exogenous reduction technology.

Finally, consider the climate dynamics for BaU scenarios in Figure 17. Again, one can see that for the case of directed technical change the outcome ranges from catastrophic, in the case of dirty growth with a temperature increase up to $8^{\circ} \mathrm{C}$, to moderate for the optimistic one of the clean growth scenario with an increase of 


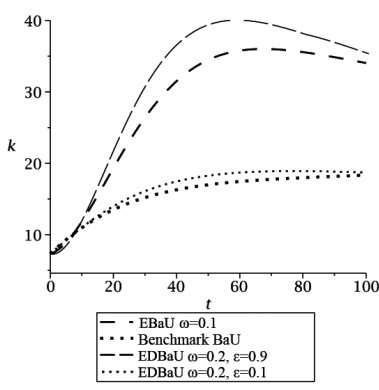

(a) Capital dynamics

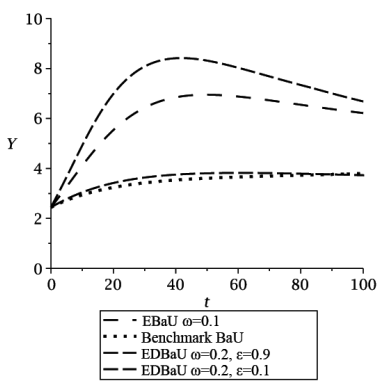

(b) Output dynamics

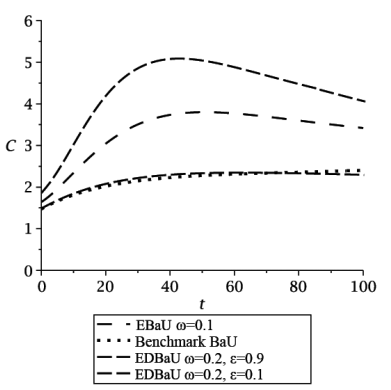

(c) Consumption dynamics

Fig. 15: Economic dynamics for BaU scenarios

only $3^{\circ} \mathrm{C}$. BaU model and $\mathrm{EBaU}$ model dynamics lie within this range in the same way as for full information models. At the same time, the increase in emissions and temperature for $\mathrm{BaU}$ scenarios is much higher for all three models being considered and is not stabilizing in the long-run. In the full information case, there exists at least one scenario (clean growth) with a stabilizing temperature, while this is not the case for BaU simulations.

Table 6 gives the relative welfare losses and gains, expressed in present value consumption, for the EBaU and EDBaU scenarios in comparison with the $\mathrm{BBaU}$ and $\mathrm{EBaU}$ scenarios. From this table, one can see that both the model with undirected

Table 6: Present value consumption changes between $\mathrm{BaU}$ scenarios

\begin{tabular}{lcc}
\hline Scenario & $t=50$ & $t=100$ \\
\hline EBaU/BBaU & $48.89 \%$ & $51.64 \%$ \\
EDBaU(dirty)/BBaU & $98.15 \%$ & $98.23 \%$ \\
EDBaU(neutral)/BBaU & $41.58 \%$ & $43.56 \%$ \\
EDBaU(clean)/BBaU & $2.43 \%$ & $1.48 \%$ \\
EDBaU(dirty)/EBaU & $33.09 \%$ & $30.72 \%$ \\
EDBaU(neutral)/EBaU & $-4.90 \%$ & $-5.32 \%$ \\
EDBaU(clean)/EBaU & $-31.20 \%$ & $-33.08 \%$
\end{tabular}

and directed endogenous technical change yield higher social welfare than the basic model with exogenous technology, even if environmental damages are higher in 


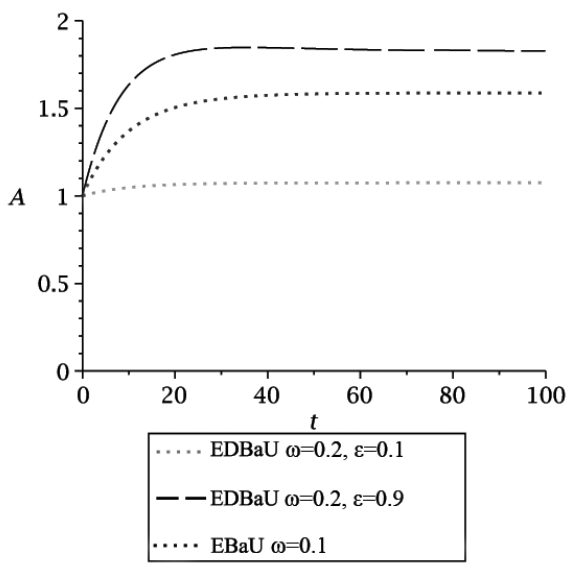

(a) Productivity growth

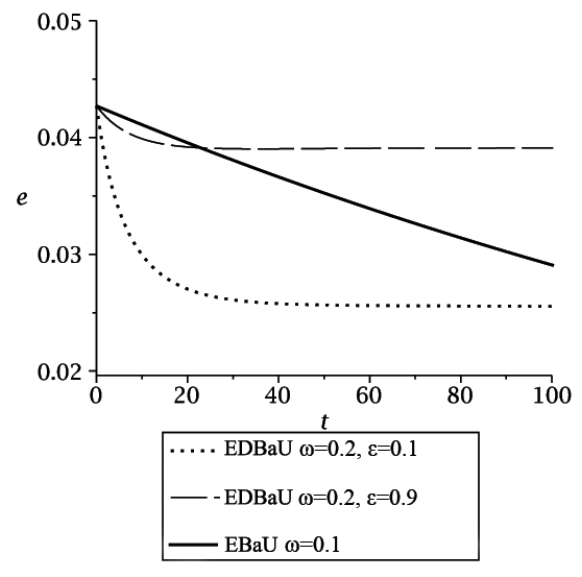

(b) Reduction of emissions intensity

Fig. 16: Technology for BaU models

almost all cases (except the clean growth scenario). The clean growth scenario yields almost the same welfare as the BaU scenario with exogenous technical change, but with stabilized emissions and temperature. In addition, the dirty growth scenario with directed technical change yields higher social welfare than the scenario with undirected technical change in $\mathrm{BaU}$ scenarios in the same way as in the case of optimal strategies. For clean and neutral technical change, one sees that directed technical change leads to a loss of social welfare compared to the scenario with undirected technical progress for $\mathrm{BaU}$ strategies, whereas with optimal strategies the neutral growth scenario with directed technical change exhibits higher welfare than the model with undirected technical change.

One can conclude that even in $\mathrm{BaU}$ scenarios there is a way to improve the environment without incurring social welfare losses. This is the case in the clean growth scenario where capital accumulation is reduced in order to invest in clean technologies that generate less GHG emissions. On the other hand, accelerated productivity growth in the scenario with directed technical change can lead to social welfare gains, however, at the expense of higher environmental losses for BaU strategies. The best performance among BaU scenarios is obtained for the undirected endoge- 


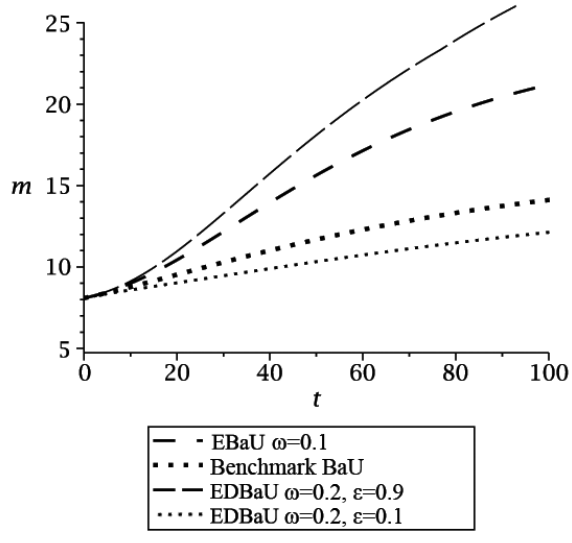

(a) GHG concentration

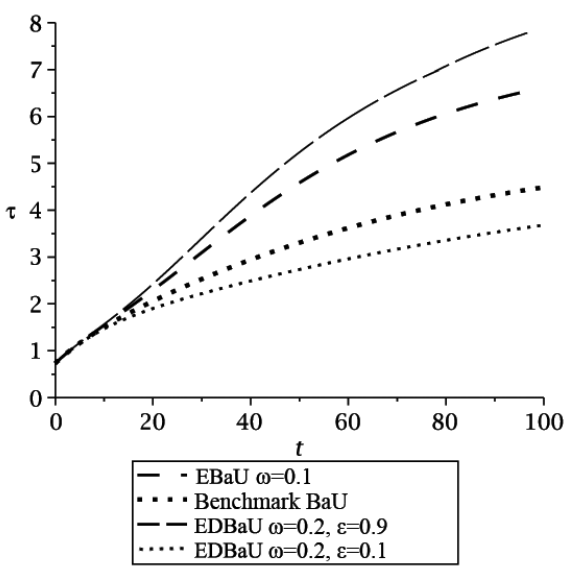

(b) Temperature increase

Fig. 17: Climate module for $\mathrm{BaU}$ scenarios

nous technical change, while models with directed technical progress display the highest diversity of possible outcomes and, thus, a high potential for policy.

\section{Conclusion}

In this paper we have analysed how technical change affects climate dynamics and economic variables in a basic growth model. We found that endogenous undirected technical change yields less greenhouse gas emissions and a lower temperature increase than the model with exogenous technical progress. This holds for the version of the model with full information but not for the informationally constrained version, where the optimizing agent neglects the influence of economic and R\&D activities on the environment. Concerning welfare, a better outcome in the case of endogenous technical change can be only guaranteed for a sufficiently high efficiency of the technology in use when the agent behaves optimally. 
In the case of directed technical change, where a certain fraction of the technical progress raises efficiency of production while the rest is devoted to the emissions intensity reduction, results are more complicated. In the green growth scenario with a large fraction of technical progress devoted to the emissions intensity reduction, the rise in temperature is clearly smaller compared to the model of undirected endogenous technical change. However, that goes at the cost of output and consumption such that the green growth scenario implies lower welfare than the model with undirected technical progress. That also holds for the informationally constrained version of the model.

The introduction of informational constraints decreases the consumption paths in all versions of the model and under all of the scenarios of technical change being considered. The higher is the degree to which the central authority may influence the technology, the more drastic are the differences between the outcome under full information and under informational constraint of the type being considered here. However, in the class of informationally constrained economies it is possible to implement the clean growth scenario, since this one yields a higher present value consumption, i.e. higher welfare, than the scenario with exogenous technical progress. At the same time, the scenario of dirty growth is preferable under both full information and under informational constraints on the economy. If the informationally constrained central authority is allowed to choose between undirected and directed technical change, he/she will choose the dirty growth scenario. However, the simulations demonstrate that the fixed direction of technical change might be the key factor for the dirty growth alternative to be preferred by the agent. The option of control over this direction of technical change may stimulate some dynamic adjustments in the R\&D policy of the agent after some initial period of accumulation of productivity.

\section{Appendix}

\section{Optimality Conditions}

The basic model with exogenous technical change contains 3 state variables and 2 controls. The (current-value) Hamiltonian associated with this problem is:

$$
\begin{array}{r}
\mathscr{H}^{B}\left(k, \tau, m, \psi_{k}, \psi_{\tau}, \psi_{m}\right)=\frac{\left[u(t) A(t) \phi(\tau(t)) k(t)^{\alpha}\right]^{1-\gamma}}{1-\gamma}+ \\
\psi_{k}(t)\left[-\delta k(t)+\left[1-u(t)-c_{1}(a(t))\right] A(t) \phi(\tau(t)) k(t)^{\alpha}\right]+ \\
\psi_{\tau}(t)[-\lambda(m(t)) \tau(t)+d(m(t))]+ \\
+\psi_{m}(t)\left[-v m(t)+(1-a(t)) e(t) A(t) \phi(\tau(t)) k(t)^{\alpha}+E(\tau(t))\right] .
\end{array}
$$

Yielding first-order conditions on controls $u(t), a(t)$ : 


$$
\begin{gathered}
\frac{\partial \mathscr{H}^{B}}{\partial u}=\frac{\left[A(t) \phi(\tau(t)) k(t)^{\alpha}\right]^{1-\gamma}}{u}-\psi_{k}(t) A(t) \phi(\tau(t)) k(t)^{\alpha}=0 \\
\frac{\partial \mathscr{H}^{B}}{\partial a}=-A(t) \phi(\tau(t)) k(t)^{\alpha}\left(\psi_{k}(t) \frac{\partial c_{1}(a)}{\partial a}+\psi_{m} e(t)\right)=0 .
\end{gathered}
$$

and co-state equations:

$$
\begin{array}{r}
\dot{\psi}_{k}=\left(-\phi(\tau) e A \alpha k^{\alpha-1}+a \phi(\tau) e A \alpha k^{\alpha-1}\right) \psi_{m}+ \\
\left(r+\phi(\tau) A \alpha c_{1}(a) k^{\alpha-1}+\delta-\phi(\tau) A \alpha k^{\alpha-1}+u \phi(\tau) A \alpha k^{\alpha-1}\right) \psi_{k}- \\
u \phi(\tau)\left(u A \phi(\tau) k^{\alpha}\right)^{-\gamma} A \alpha k^{\alpha-1} ; \\
\dot{\psi}_{\tau}=\left(-e \cdot A \frac{\partial \phi(\tau)}{\partial \tau} k^{\alpha}+e A \frac{\partial \phi(\tau)}{\partial \tau} k^{\alpha} a\right) \psi_{m}+ \\
\left.\frac{\partial \phi(\tau)}{\partial \tau} k^{\alpha}+u A \frac{\partial \phi(\tau)}{\partial \tau} k^{\alpha}+A \frac{\partial \phi(\tau)}{\partial \tau} k^{\alpha} c_{1}(a)\right) \psi_{k}+ \\
(r+\lambda(m)) \psi_{\tau}- \\
\dot{\psi}_{m}=(r+v) \psi_{m}-\psi_{\tau} \frac{\partial d(m)}{\partial m}+\psi_{\tau} \frac{\partial \lambda(m)}{\partial m} \tau .
\end{array}
$$

These equations are non-linear and do not separate from the state equations, which makes analytic closed-form solution difficult to achieve. Therefore, we have used numerical simulations to approximate the dynamics.

In the case of undirected endogenous technical change the (current-value) Hamiltonian is given by:

$$
\begin{array}{r}
\mathscr{H}^{E}\left(k, \tau, m, x, \psi_{k}, \psi_{\tau}, \psi_{m}, \psi_{x}\right)=\frac{\left[u(t)(1+\omega x(t)) \phi(\tau(t)) k(t)^{\alpha}\right]^{1-\gamma}}{1-\gamma}+ \\
\psi_{k}(t)\left(-\delta k(t)+\left[1-u(t)-c_{1}(a(t))-c_{1}(g(t))\right](1+\omega x(t)) \phi(\tau(t)) k(t)^{\alpha}\right)+ \\
\psi_{\tau}(t)(-\lambda(m(t)) \tau(t)+d(m(t)))+ \\
\left.\psi_{m}(t)\left(-v m(t)+(1-a(t)) e(t)(1+\omega x(t)) \phi(\tau(t)) k(t)^{\alpha}\right)\right)+
\end{array}
$$




$$
\psi_{x}(t)\left(\beta_{1} g(t)-\beta_{2} x(t)\right)
$$

First-order conditions on controls $u(t), a(t), g(t)$ :

$$
\begin{gathered}
\frac{\partial \mathscr{H}^{E}}{\partial u}=\frac{\left[(1+\omega x(t)) \phi(\tau(t)) k(t)^{\alpha}\right]^{1-\gamma}}{u}-\psi_{k}(t)(1+\omega x(t)) \phi(\tau(t)) k(t)^{\alpha}=0 ; \\
\frac{\partial \mathscr{H}^{E}}{\partial a}=-(1+\omega x(t)) \phi(\tau(t)) k(t)^{\alpha}\left(\psi_{k}(t) \frac{\partial c_{1}(a)}{\partial a}+\psi_{m}(t) e(t)\right)=0 ; \\
\frac{\partial \mathscr{H}^{E}}{\partial g}=-(1+\omega x(t)) \phi(\tau(t)) k(t)^{\alpha} \psi_{k}(t) \frac{\partial c_{1}(g)}{\partial g}+\beta_{1} \psi_{x}(t)=0 .
\end{gathered}
$$

With directed endogenous technical change, the first-order conditions from the Hamiltonian (of the same type as for undirected change) are:

$$
\begin{array}{r}
\frac{\partial \mathscr{H}^{D}}{\partial u}=\frac{\left[(1+\varepsilon \omega x(t)) \phi(\tau(t)) k(t)^{\alpha}\right]^{1-\gamma}}{u}-\psi_{k}(t)(1+\omega x(t)) \phi(\tau(t)) k(t)^{\alpha}=0 \\
\frac{\partial \mathscr{H}^{D}}{\partial a}=-(1+\varepsilon \omega x(t)) \phi(\tau(t)) k(t)^{\alpha}\left(\psi_{k}(t) \frac{\partial c_{1}(a)}{\partial a}+\psi_{m}(t) \frac{e_{0}}{1+(1-\varepsilon) \omega x(t)}\right)=0 \\
\frac{\partial \mathscr{H}^{D}}{\partial g}=-(1+\varepsilon \omega x(t)) \phi(\tau(t)) k(t)^{\alpha} \psi_{k}(t) \frac{\partial c_{1}(g)}{\partial g}+\beta_{1} \psi_{x}(t)=0 .
\end{array}
$$

\section{The NMPC Technique}

The full dynamical system, which describes the evolution of economic and environmental variables, consists of 3 (in the case of the basic model) or 4 (for endogenous technology) dynamical equations. Consider, for example, the dynamical system for directed endogenous technology:

$$
\begin{array}{r}
\dot{k}(t)=-\delta k(t)+\left[1-u(t)-c_{1}(a(t))-c_{1}(g(t))\right] Y(t) ; \\
\dot{\tau}(t)=-\lambda \tau(t)+\ln \frac{m(t)}{m_{0}^{*}} ; \\
\dot{m}(t)=-v m(t)+(1-a(t)) e^{D}(t)(1+\varepsilon \omega x(t)) k^{\alpha}(t) ; \\
\dot{x}(t)=\beta_{1} g(t)-\beta_{2} x(t) .
\end{array}
$$


At the same time the agent solves the optimization problem that depends only on economic and technology variables for each period $\left[t_{h}, \ldots, t_{h}+\Theta\right]$, assuming environmental variables being constant on the level of the last measurement:

$$
\begin{gathered}
J^{E D B a U}=\max _{u, g}\left\{\int_{t_{h}}^{t_{h}+\Theta} e^{-r t} \cdot\left(\frac{[u(t) Y(t)]^{1-\gamma}}{1-\gamma}\right) d t\right\} \\
\text { s.t. } \\
\left.\dot{k}_{i}(t)=-\delta k_{i}(t)+\left[1-u(t)-c_{1}(g(t))\right)\right] Y(t) ; \\
\dot{x}(t)=\beta_{1} g(t)-\beta_{2} x(t) ; \\
Y_{i}(t)=A^{D}(t) \phi\left(\tau_{i}\right) k_{i}(t)^{\alpha} ; \\
A^{D}(t)=1+\varepsilon \omega x(t) ; \\
\tau_{i}=\tau\left(t_{i}\right) .
\end{gathered}
$$

where $Y_{i}(t), k_{i}(t)$ are different from the true evolution of capital, $k(t)$, and output, $Y(t)$, and are defined from the reduced problem without environmental constraints. This "capital" defines the optimal consumption share of an agent, while the consumption is defined from the true capital and output, given by the evolution of the system Eq. (20). With such a problem the Hamiltonian of the agent contains only two constraints (on "capital" and technology):

$$
\begin{array}{r}
\mathscr{H}^{E D B a U}\left(k_{i}, x, \psi_{k_{i}}, \psi_{x}\right)=\frac{\left[u(t)(1+\varepsilon \omega x(t)) \phi\left(\tau_{i}\right) k_{i}(t)^{\alpha}\right]^{1-\gamma}}{1-\gamma}+ \\
\psi_{k_{i}}(t)\left(-\delta k_{i}(t)+\left[1-u(t)-c_{1}(g(t))\right](1+\varepsilon \omega x(t)) \phi\left(\tau_{i}\right) k_{i}(t)^{\alpha}\right)+ \\
\psi_{x}(t)\left(\beta_{1} g(t)-\beta_{2} x(t)\right) .
\end{array}
$$

and one may define only consumption share and technology investments, but not abatement rates from such a problem. Abatement rates are equal to zero for all $\mathrm{BaU}$ problems considered under this scheme.

The same type of logic of construction is applied for all three versions of the model: basic one, with undirected endogenous technical change and with the directed one. To obtain solutions in the $\mathrm{BaU}$ case we make use of the numerical methods, since no analytic solution may be derived for this NMPC technique. We also obtain numeric solutions for full problems of the type Eq. (1) s.t. (2) - (7). 


\section{References}

[1] Acemoglu D, Aghion P, Bursztyn L, Hemous D (2012) The environment and directed technical change. American Economic Review 102(1):131-66

[2] Aghion P, Howitt P (1992) A model of growth through creative destruction. Econometrica 60(2):323-351

[3] Allgöwer F, Zheng A (2006) Nonlinear model predictive control. Springer

[4] Barbier E (1999) Endogenous growth and natural resource scarcity. Environmental and Resource Economics 14(1):51-74

[5] Bréchet T, Camacho C, Veliov V (2010) Model predictive control, the economy, and the issue of global warming. Annals of Operations Research pp 1-24

[6] Grimaud A (1999) Pollution permits and sustainable growth in a schumpeterian model. Journal of Environmental Economics and Management 38(3):249266

[7] Grimaud A, Rougé L (2003) Non-renewable resources and growth with vertical innovations: optimum, equilibrium and economic policies. Journal of Environmental Economics and Management 45(2):433-453

[8] Grimaud A, Rougé L (2005) Polluting non-renewable resources, innovation and growth: welfare and environmental policy. Resource and Energy Economics 27(2):109-129

[9] Hassler J, Krusell P (2012) Economics and climate change: Integrated assessment in a multi-region world. Working Paper 17757, National Bureau of Economic Research, URL http://www.nber.org/papers/w17757

[10] Lans Bovenberg A, Smulders S (1995) Environmental quality and pollutionaugmenting technological change in a two-sector endogenous growth model. Journal of Public Economics 57(3):369-391

[11] Ligthart J, Van Der Ploeg F (1994) Pollution, the cost of public funds and endogenous growth. Economics Letters 46(4):339-349

[12] Nordhaus W (2007) The challenge of global warming: economic models and environmental policy, vol 4. Yale University

[13] Romer P (1990) Endogenous technological change. The Journal of Political Economy 98(5):S71-S102

[14] Smulders S, Gradus R (1996) Pollution abatement and long-term growth. European Journal of Political Economy 12(3):505-532 